\title{
Nylon 6 Polymerization in the Solid State
}

\author{
REINOUD J. GAYMANS, JOHN AMIRTHARAJ, and HENK KAMP, \\ Twente University of Technology, Dept. of Chemical Technology, Polymer \\ Laboratories, 7500 AE Enschede, The Netherlands
}

\begin{abstract}
Synopsis
The postcondensation of nylon 6 in the solid state was studied. The reactions were carried out on fine powder in a fluidized bed reactor in a stream of dry nitrogen in the temperature range $110-205^{\circ} \mathrm{C}$ and during $1-24 \mathrm{~h}$. The solid-state polymerization (SSP) did not follow melt kinetics, but was found to be limited by the diffusion of the autocatalyzing acid chain end group. Factors thought to influence SSP were studied, e.g., heat treatment, starting molecular weight, and remelting. Surprisingly, heat treatment had little effect, but the starting molecular weight had a strong effect on the reaction rate. The higher the starting molecular weight, the faster the reaction. This could be explained as a changing concentration distribution of the reactive groups in the solid state on SSP. The kinetics of the SSP had more than one region, and the rate of reaction for conversions of over $30 \%$ could be expressed as $-d c / d t=k(c / t)$, where $k$ is a dimensionless constant independent of temperature with a value of 0.28 . The integrated form has the form $-\ln \left(c / c_{0}\right)=k \ln (t / \tau)$, where $c_{0}$ is the acid end-group concentration at the start, $t$ is the reaction time, and $\tau$ is the induction time. The value of $\tau$ is both dependent on the starting concentration $c_{0}$ and the reaction temperature and has an activation energy of $105 \mathrm{~kJ} / \mathrm{mol}$.
\end{abstract}

\section{INTRODUCTION}

Postcondensation of polyamides in the solid state has been known for many years, ${ }^{1,2}$ and the method is used in industry to produce high-molecular-weight materials for tyre cords and engineering plastics. Despite its widespread application, very little has been published about its mechanism and kinetics. Surprising too is that at temperatures well below the melting temperature of the polymer, still fairly high reaction rates are obtained. ${ }^{1}$

In a melt polymerization, the rate of reaction depends on the amine and acid end-group concentration,

$$
-\frac{d c}{d t}=k[\text { acid }]\left[-\mathrm{NH}_{2}\right][-\mathrm{COOH}]
$$

and the reaction is acid catalyzed. ${ }^{3}$ The polymerization in the solid state does not follow the melt polymerization kinetics. ${ }^{2-6}$ The reaction seems to be slowed down by diffusion. The limiting process might be the diffusion of the condensate out of the particle or the diffusion of the reactive end groups in the solid.

The condensate $\left(\mathrm{H}_{2} \mathrm{O}\right)$ diffusion has been studied with samples of varying particle size ${ }^{4}$ and the influence of the particle size on the rate of reaction was found to be small. In the solid-state polymerization (SSP), the diffusion of the reacting end groups must then be the limiting process. Sokolov ${ }^{2}$ suggested in his review on polycondensation in the solid state that the crystalline phase has a major influence on the diffusion rate of the reactive end groups. 
TABLE I

Influence of Starting Molecular Weight on SSP of Nylon 6,6 at $216^{\circ} \mathrm{C}$ a

\begin{tabular}{ccc}
\hline & & Hours to reach $\bar{M}_{0}$ \\
$\bar{M}_{\mathrm{n}}$ & R.V. & 15,000 (R.V.87) \\
\hline 1000 & 3.5 & 16 \\
2500 & 5.5 & 4 \\
4000 & 8.5 & 2 \\
\hline
\end{tabular}

From Monroe. ${ }^{10}$

Griskey et al. ${ }^{4,5}$ studied the SSP of nylon 6,6 and nylon 6,10 and also found the reaction to be reactive end-group diffusion limited. They presented, in accordance with standard practice in solid-state chemistry, the reaction rate as a time function:

$$
-\frac{d c}{d t}=k t^{n}
$$

For nylon 6,6 , they found $n$ to be -0.5 , and $k$ had an activation energy of 10.5$12.96 \mathrm{kcal} / \mathrm{mol}(44.0-54.3 \mathrm{~kJ} / \mathrm{mol})$. For nylon $6,10, n$ was -1.0 , and the activation energy was $13.2 \mathrm{kcal} / \mathrm{mol}(55.3 \mathrm{~kJ} / \mathrm{mol})$.

Oya et al. ${ }^{6}$ studied the SSP of nylon 6 and found that the reaction had two stages which were both first order:

$$
-\frac{d c}{d t}=k c
$$

Each stage had its own $k$ value; $k_{2}$ had approximately double the value of $k_{1}$. The activation energies were $38.1 \mathrm{kcal} / \mathrm{mol}(159 \mathrm{~kJ} / \mathrm{mol})$ for $E_{1}$ and $32.1 \mathrm{kcal} / \mathrm{mol}(134$ $\mathrm{kJ} / \mathrm{mol}$ ) for $E_{2}$. They thought that the amine and acid end groups which have to react are already coupled and have a zwitterion structure

$$
m \mathrm{NH}_{2}+\mathrm{HOOC} m \rightleftarrows m \mathrm{NH}_{3}^{+} \frac{0}{0}-\mathrm{C} m
$$

so they need not diffuse to react. As most amine and acid end groups are coupled and have the zwitterion structure, only the autocatalyzing acid group has to diffuse for the reaction to take place. This autocatalytic acid diffusion seems thus the limiting process.

If in the solid-state polymerization low-molecular-weight acids, e.g., $\mathrm{H}_{3} \mathrm{PO}_{4}{ }^{7}$ $\mathrm{HBO}_{3},{ }^{8}$ and $\mathrm{H}_{2} \mathrm{SO}_{4},{ }^{9}$ are added, the reaction is speeded up. The reaction is also influenced by the starting molecular weight of the sample. Monroe, ${ }^{10}$ studying nylon 6,6 , found that the higher the starting molecular weight of the sample, the faster the rate of reaction (Table I).

The rate of reaction in going from MW 1000 to 4000 is always very fast, and hence the reaction time between MW 4000 and 15,000 is increasing with decreasing starting molecular weight. Although the reaction time in the $1000-4000$ region is short, it seems to have a major influence on the rate in the $4000-15,000$ region. This effect is still unexplained.

A diffusion-limited reaction rate is dependent on the diffusion rate and the diffusion distance. If the diffusion rate is thought to be constant for a particular material at a particular temperature and the diffusion distance just to be de- 
pendent on the concentration of the reactive end group, then the effect of the starting molecular weight cannot be explained. So either the diffusion rate or the diffusion distance must be a function of the reaction history in the solid state, too. In order to get more insight in the SSP, these have to be better understood.

\section{Diffusion Rate of the Chain End Groups}

In a semicrystalline material, the diffusion rate of the chain end groups must be a function of the molecular mobility of these groups. The chain end groups are thought to be part of the amorphous phase and sticking out of the crystalline phase. The molecular mobility will probably depend on both the size and perfection of the crystalline phase and the packing of the amorphous phase. Sokolov $^{2}$ suggested that the crystalline phase has a major influence on the diffusion rate of the reactive end groups. The effect of heat treatment on the molecular mobility of nylon 6 has been studied by NMR. Wangermann and Zachmann ${ }^{11}$ found that with heat treatment, the mobility of the amorphous phase did not decrease and even seemed to increase. These results suggest that heat treatment will not decrease the diffusion rate of the chain end groups. The theory of Sokolov and the results of Wangermann and Zachmann seem to be conflicting.

\section{Diffusion Distance of the Chain End Groups}

The diffusion distance depends on the end-group concentration and its distribution. In a well-stirred system, there is a homogeneous distribution. In the SSP, a change in end-group distribution away from the homogeneous distribution is possible as some of the nearest end groups are reacting away while others are kept frozen in.

This process is visualized in Figure 1. Curve 1a represents a sample just cooled from the melt in which there is a homogeneous distribution of the end groupto-end group distances. Curve $1 \mathrm{~b}$ gives a hypothetical distribution after some SSP of sample 1a. The end groups with the smallest end-to-end distances have reacted away while the others have virtually kept frozen in. Curve 1c represents a sample with the same end-group concentration as $1 \mathrm{~b}$ but now homogeneously distributed. The question is whether the SSP samples have the $1 \mathrm{~b}$ or $1 \mathrm{c}$ distribution. If the $1 \mathrm{~b}$ end-to-end distribution is followed, then the diffusion distance does not only depend on the concentration but also on the gradually changing end-to-end distance distribution with the progress of the reaction in the solid state.

From the foregoing its seems more likely that by the SSP the diffusion distance is a function of the progress of the reaction than the diffusion rate being a function of the heat treatment.

In this article, we firstly try to demonstrate that the autocatalytic acid diffusion is the reaction rate-limiting step in the SSP; secondly we hope to discriminate the sample history effect on either the diffusion rate or the diffusion distance; and thirdly we try to develop a new kinetic relationship for the SSP. 


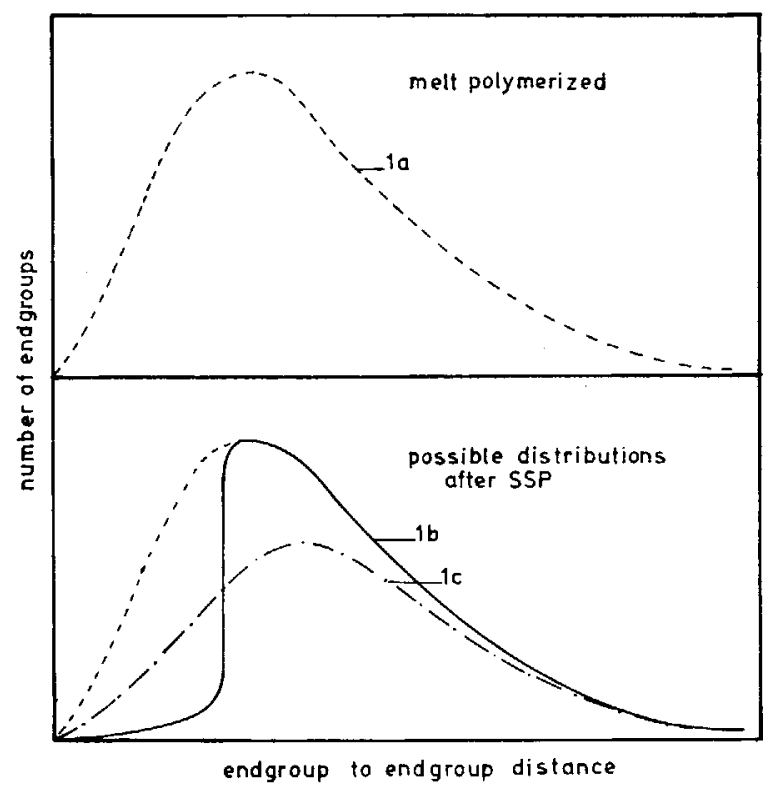

Fig. 1. End group-to-end group distance distribution changes on SSP: (1a) starting material just cooled from the melt; (1b) distribution of the SSP with limiting diffusability; (1c) Distribution of the SSP with no diffusion limitation and/or distribution after remelting.

\section{EXPERIMENTAL}

\section{Materials}

The starting polymers were prepared from caprolactam (kindly provided by DSM) and polymerized in the presence of water in a glass capsule. For safety reasons, the capsule was placed in an autoclave. ${ }^{12}$ In a typical synthesis, $5 \%$ water was employed and reacted for $4 \mathrm{~h}$ at $240^{\circ} \mathrm{C}$.

The reaction mass was ground to a particle size of $0.2-0.5 \mathrm{~mm}$. The lactam in the sample was extracted with boiling methanol. A list of starting materials is given in Table II.

\section{Solid-State Polymerization}

The solid-state polymerization (SSP) was conducted in a glass fluidized bed reactor (Fig. 2) $2.5 \mathrm{~cm}$ in diameter, $50 \mathrm{~cm}$ long, and fitted with a sintered glass filter (size G2) at the bottom. Through this filter, oxygen-free preheated gas flowed into the reactor at a rate of $20 \mathrm{~cm}^{3} / \mathrm{s}$. The flowing gas warmed up the particles evenly and carried away the condensate $\left(\mathrm{H}_{2} \mathrm{O}\right)$.

The sample could be inserted before warming up the reactor, but provisions were also made to bring the sample into the heated reactor. In this way, the sample was in $2-3 \mathrm{~min}$ on temperature. The temperature in the reactor could be controlled to $0.2^{\circ} \mathrm{C}$. The reactions were stopped by removing the reactor from the oven. 
TABLE II

Starting Materials

\begin{tabular}{|c|c|c|c|c|c|c|c|c|c|c|}
\hline \multirow[b]{4}{*}{ Sample } & \multicolumn{3}{|c|}{ Reaction conditions } & \multirow{2}{*}{\multicolumn{4}{|c|}{ End-group analysis }} & \multirow{3}{*}{\multicolumn{3}{|c|}{$\begin{array}{c}\text { Viscometry } \\
(85 \% \mathrm{H} \mathrm{COO} \mathrm{H})\end{array}$}} \\
\hline & \multirow{3}{*}{$\begin{array}{c}\text { Water } \\
\text { conc., } \\
\% \\
\end{array}$} & \multirow[b]{3}{*}{ Addition } & \multirow{3}{*}{$\begin{array}{c}\text { Temp. } \\
{ }^{\circ} \mathrm{C}\end{array}$} & & & & & & & \\
\hline & & & & \multirow{2}{*}{$\begin{array}{c}\text { Time, } \\
\mathrm{h}\end{array}$} & \multirow{2}{*}{$\begin{array}{l}{\left[-\mathrm{NH}_{2}\right]} \\
(\mathrm{meq} / \mathrm{g})\end{array}$} & \multirow{2}{*}{$\begin{array}{c}{[-\mathrm{COOH}]} \\
(\mathrm{meq} / \mathrm{g})\end{array}$} & \multirow{2}{*}{$\begin{array}{c}\bar{M}_{n} \\
\text { (meq/g) }\end{array}$} & & & \\
\hline & & & & & & & & $\overline{\eta_{\text {rel }}}$ & $\eta_{\text {inh }}$ & $\bar{M}_{v}$ \\
\hline A & 20 & - & 240 & 4 & 0.404 & 0.400 & 2,500 & 1.20 & 0.182 & 3,600 \\
\hline B & 10 & - & 240 & 4 & 0.256 & 0.246 & 4,000 & 1.30 & 0.259 & 5,800 \\
\hline $\mathrm{C}$ & 5 & - & 240 & 4 & 0.159 & 0.158 & 6,300 & 1.41 & 0.346 & 8,300 \\
\hline D & $\begin{array}{r}\text { Samp } \\
\text { SS } \\
190^{\circ}\end{array}$ & $\begin{array}{l}\text { A subjec } \\
\text { for } 35 \mathrm{mi} \\
\mathrm{C} \text { and rem }\end{array}$ & $\begin{array}{l}\text { ted to } \\
n \text { at } \\
\text { elted }\end{array}$ & & 0.117 & 0.129 & 8,100 & 1.53 & 0.426 & 10,900 \\
\hline $\mathrm{E}$ & 1.3 & - & 240 & 6 & 0.092 & 0.093 & 10,800 & 1.71 & 0.531 & 14,800 \\
\hline$F$ & 0.4 & - & 240 & 24 & 0.053 & 0.054 & 18,700 & 2.43 & 0.884 & 31,500 \\
\hline G & 5 & $\begin{array}{c}\mathrm{H}_{3} \mathrm{PO}_{4} \\
0.1 \%\end{array}$ & 240 & 4 & 0.150 & 0.168 & 6,300 & 1.40 & 0.339 & 8,000 \\
\hline
\end{tabular}

\section{Characterization}

Amine end groups were potentiometrically titrated in phenol/water solutions ${ }^{13}$ and the carbonyl end groups in benzyl alcohol. ${ }^{14}$ The viscosities were determined on $1 \%$ solutions in $85 \%$ formic acid. From the inherent viscosity, $\bar{M}_{v}$ was calculated ${ }^{15}$ as follows:

$$
\begin{gathered}
\eta_{\text {inh }}=[\eta]-k_{k}[\eta]^{2} C \\
{[\eta]=22.6 \times 10^{-3} \bar{M}_{v}^{0.85}}
\end{gathered}
$$

For $k_{k}$, a value of 0.18 was used.

\section{RESULTS AND DISCUSSION}

\section{Autocatalytic Acid Diffusion}

The autocatalytic polymerization of nylon 6 in the solid phase in a stream of dry nitrogen has a fast initial reaction, but the speed was gradually slowed down with reaction time (Fig. 3). Solid-state polymerization (SSP) does not follow second- or third-order reaction kinetics, while for melt polymerization a third-

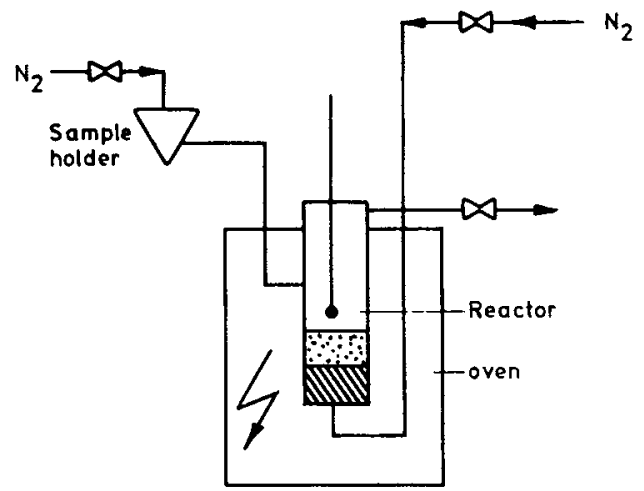

Fig. 2. Fluidized bed reactor. 


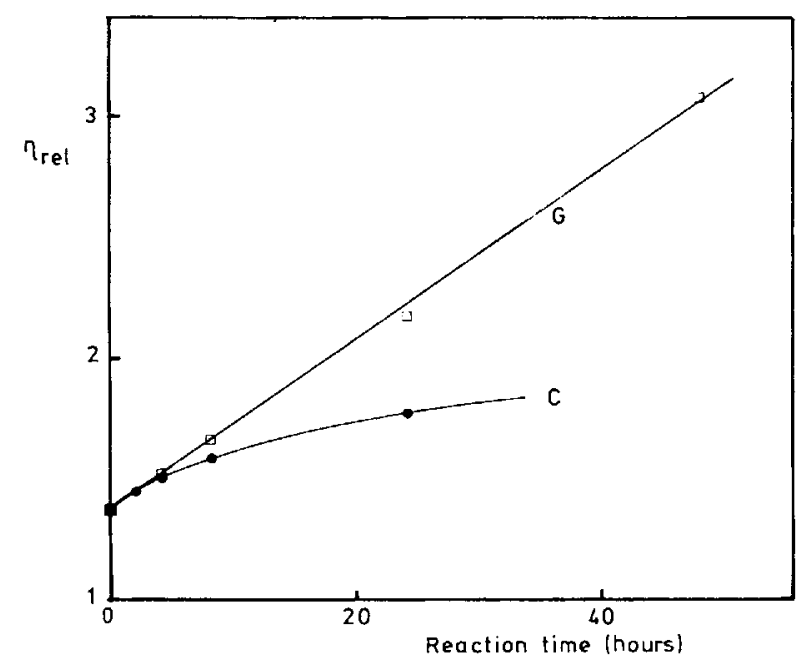

Fig. 3. Autocatalytic SSP vs. $\mathrm{H}_{3} \mathrm{PO}_{4}$-catalyzed reactions at $145^{\circ} \mathrm{C}$ : (•) sample C autocatalytic (without additions); (ם) sample $\mathrm{G}$ with $0.1 \% \mathrm{H}_{3} \mathrm{PO}_{4}$.

order kinetics is predominant. ${ }^{2}$ The apparent order of reaction of the SSP calculated from these data was four to five.

A sample with $0.1 \% \mathrm{H}_{3} \mathrm{PO}_{4}$ and SSP under the same reaction conditions reacted faster (Fig. 3). The initial rate is comparable to that of the autocatalyzed sample, but the reaction progressed differently. The $\mathrm{H}_{3} \mathrm{PO}_{4}$ concentration in sample $\mathrm{G}$ was $0.1 \%$, or $0.01 \mathrm{mmol} / \mathrm{g}$. If of this acid only the first dissociation step is taken into account, then it was $0.01 \mathrm{meq} / \mathrm{g}$ acid groups which take part in the reaction. In as much as this is only a fraction of the total acid concentration of this sample $([-\mathrm{COOH}]=0.168 \mathrm{meq} / \mathrm{g})$, the presence of $\mathrm{H}_{3} \mathrm{PO}_{4}$ does not so much affect the total acid concentration. As the total concentration in sample $\mathrm{G}$ is only slightly increased and the initial rate of reaction (no diffusion limitation yet) is similar to that of the autocatalytic sample, this suggest that $\mathrm{H}_{3} \mathrm{PO}_{4}$ has no special catalytic effect. The advantage of the low-molecular-weight acid $\mathrm{H}_{3} \mathrm{PO}_{4}$ must be that it is not incorporated in the polymer chain and diffuses faster.

The SSP of sample C (autocatalyzed) did not follow melt polymerization kinetics. The reaction slowed down with reaction time and was slower than that of sample $\mathrm{G}$ which contained an easy diffusable acid. From this it seems that in the absence of $\mathrm{H}_{3} \mathrm{PO}_{4}$, the reaction rate is limited by the diffusion of the autocatalyzing acid chain end group.

\section{Diffusion Rate and Diffusion Distance}

The rate of reaction in SSP depends on the diffusion rate (molecular mobility) and the diffusion distance. As has been pointed out in the introduction, it is expected that either of these two are a function of the reaction history. The diffusion rate might depend on the heat treatment and the diffusion distance on a changing end group-to-end group distance distribution. 


\section{Heat Treatment}

The effect of heat treatment on the rate of SSP was studied in three ways: by varying the warming-up rates, by varying the melt cooling procedures, and by isothermal annealing. In a standard procedure, the samples were warmed up in 2-3 min. We wondered whether this warming-up rate had an effect on the SSP.

For this purpose, a sample was warmed up in $22 \mathrm{~h}$ to $190^{\circ} \mathrm{C}\left(0.15^{\circ} \mathrm{C} / \mathrm{min}\right)$ and thereby reached a $\bar{M}_{v}$ of 19,600 . This molecular weight was also reached by fast warming up in $3 \mathrm{~min}\left(50^{\circ} \mathrm{C} / \mathrm{min}\right)$ and an additional $2 \mathrm{~h}$ reacting at $190^{\circ} \mathrm{C}$. If both samples were given $22 \mathrm{~h}$ at $190^{\circ} \mathrm{C}$, their $\bar{M}_{v}$ values were respectively 37,700 and 37,500 . Thus, the warming-up procedure had no effect on the progress of the reaction.

The starting materials we used were cooled from the melt in the autoclave at $5^{\circ} \mathrm{C} / \mathrm{min}$. As the SSP seems to be very sensitive to the initial structure of the material, we wondered whether melt quenching increases the SSP rate and annealing reduces the SSP rate. Material of sample $\mathrm{C}$ was melted in a hot press and quenched. In this procedure the molecular weight did not change. If sample $\mathrm{C}$ and the melt-quenched sample were both reacted for $24 \mathrm{~h}$ at $190^{\circ} \mathrm{C}$, their $\bar{M}_{v}$ values were respectively 36,800 and 37,600 . Hence melt quenching did not affect the rate of reaction.

Some material of sample $\mathrm{C}$ was heat treated in a closed capsule for $4 \mathrm{~h}$ at $180^{\circ} \mathrm{C}$ in the presence of $5 \%$ excess water. In this way, a strong heat treatment was given while not allowing the reaction to progress. In the $4 \mathrm{~h}$ at $180^{\circ} \mathrm{C}$, the molecular weight increased slightly from 8550 to 10,450 . The SSP of this sample, $24 \mathrm{~h}$ at $190^{\circ} \mathrm{C}$, increased the $\bar{M}_{v}$ to 47,800 while the control sample reached 36,800 in the same time. The heat treatment in the solid state did not reduce the rate of reaction, it rather increased the reaction rate. Heat treatment does not limit SSP.

\section{Starting Molecular Weight}

Under well-stirred reaction conditions, the rate of the reaction is only dependent on the actual concentrations and never on the conditions at the start of the experiment. For the polyamidation in the solid state, however, it has been observed that the reaction rate did depend on the starting molecular weight. ${ }^{10}$ We reacted samples with different starting molecular weights and starting concentrations at $190^{\circ} \mathrm{C}$. All reactions progressed very similar; but the higher the starting molecular weight or the lower the starting concentration, the faster the reaction rates were (Fig. 4, Table III). The reaction time necessary to bridge the 10,000-18,000 MW range was $22.2 \mathrm{~h}$ for sample A $\left(\bar{M}_{n_{0}}=2500\right)$, while sample $\mathrm{C}\left(\bar{M}_{n_{0}}=6300\right)$ needed $4.2 \mathrm{~h}$ and sample $\mathrm{D}\left(\bar{M}_{n_{0}}=8100\right)$, only $3.5 \mathrm{~h}$.

It is evident from this that there is an important effect of either the starting molecular weight or starting concentration on the rate of reaction. These results cannot be explained as molecular weight effect, in as much as the reaction times were all measured over the same molecular weight range, or as a heat treatment effect, as we have seen above, or as a concentration effect, as they were the same like the molecular weights over this range. Most likely these results are due to a concentration distribution or end group-to-end group distance distribution effect; this effect is schematically given in Figure 1, curves $1 \mathrm{a}$ and $1 \mathrm{~b}$. 


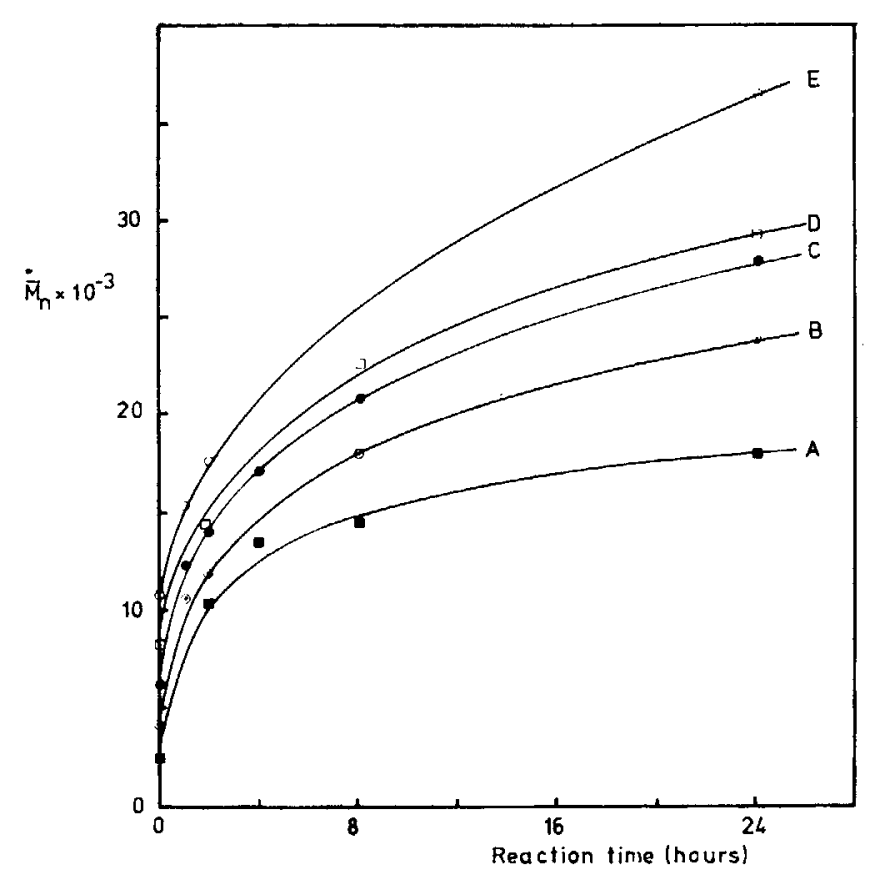

Fig. 4. Influence of starting molecular weight on progress of reaction at $190^{\circ} \mathrm{C} . \bar{M}_{n_{0}} ; \mathrm{A}, 2500$; $\mathrm{B}, 4000 ; \mathrm{C}, 6300, \mathrm{D}, 8100 ; \mathrm{E}, 10,800$.

If a sample which is given some SSP is cooled and is subjected to a second SSP, the progress of the reaction is not affected by the intermediate cooling. In this light, the reaction behavior of sample D is important. Sample D was obtained by reacting sample $A$ for $35 \mathrm{~min}$ at $190^{\circ} \mathrm{C}$ and after this the material was remelted. This sample D reacted now much faster than before the remelting. Thus, some reorganization in the material must have taken place during the remelting which had a profound effect on the SSP. By this remelting, both the crystalline structure and the end group-to-end group distance distributions might have reorganized.

We have shown above that annealing had little effect on SSP, thus reorganizing the crystalline structure by remelting is not expected to influence the SSP reaction rate much. The end group-to-end group distance distribution is always homogeneous after melting. If on SSP the distribution is changed like in Figure 1 , curve $1 b$, then remelting changes this to a homogeneous distribution as in curve 1c. Remelting allows a fresh start with a much faster rate of reaction than if the sample had not been remelted, and this can very well be explained by the distribution change from curve $1 b$ to curve $1 c$. This strengthens the hypothesis

TABLE III

Influence of $\bar{M}_{n_{0}}\left(c_{0}\right)$ on Reaction Time (at $190^{\circ} \mathrm{C}$ ) for $\bar{M}_{n} 10,000-18,000$

\begin{tabular}{|c|c|c|c|c|c|}
\hline \multicolumn{3}{|c|}{ Starting materials } & \multicolumn{3}{|c|}{ Reaction time $t, \mathrm{~h}$} \\
\hline & $\bar{M}_{n_{0}}$ & $c_{0}$ & $\overline{\text { To }}_{n} 10,000$ & To $\bar{M}_{n} 28,000$ & $\Delta t, \mathrm{~h}$, for $18,000-12,000$ \\
\hline A & 2500 & 0.400 & 2.5 & 25 & 22.5 \\
\hline $\mathrm{C}$ & 6300 & 0.158 & 0.5 & 4.5 & 4.0 \\
\hline $\mathrm{D}$ & 8100 & 0.129 & 0.4 & 3.8 & 3.4 \\
\hline
\end{tabular}


that by SSP the end group-to-end group distance distribution is changed like shown in Figure 1, curve 1b.

\section{Kinetics}

From what we have found, it appears that the SSP of nylon 6 is limited by the diffusion speed of the catalyzing acid and that this is not only dependent on the concentration and the temperature but also on the changing end group-to-end group distance distribution. This distribution gradual changes with the extent of reaction in the solid state. This diffusion limitation is often given as a time function. ${ }^{16}$ We therefore expect the rate of reaction in the solid state to depend on the concentration (of the catalyzing acid) and on time. The reaction rate function might then have the following form:

$$
-\frac{d c}{d t}=k c t^{n}
$$

The order $n$ of the time function has to be determined. Equation (b) can be rewritten as

$$
\ln \left(-\frac{d c}{d t} / c\right)=\ln k+n \ln t
$$

The results of SSP at $190^{\circ} \mathrm{C}$ of a series of samples with different starting concentrations $c_{0}$ are given in Figure 5. The proposed first order in the concentration in the reaction rate equation, eq. (6), seems to fit the reaction data rather well. As the data of all the samples seem to fall on one line, the influence of the starting concentration on the slope and the intercept can only be small. The slope gives the reaction order $n$ of the time function and was found to be -0.99 \pm 0.05 . Hence, eq. (6) can be simplified to

$$
-\frac{d c}{d t}=k \frac{c}{t}
$$

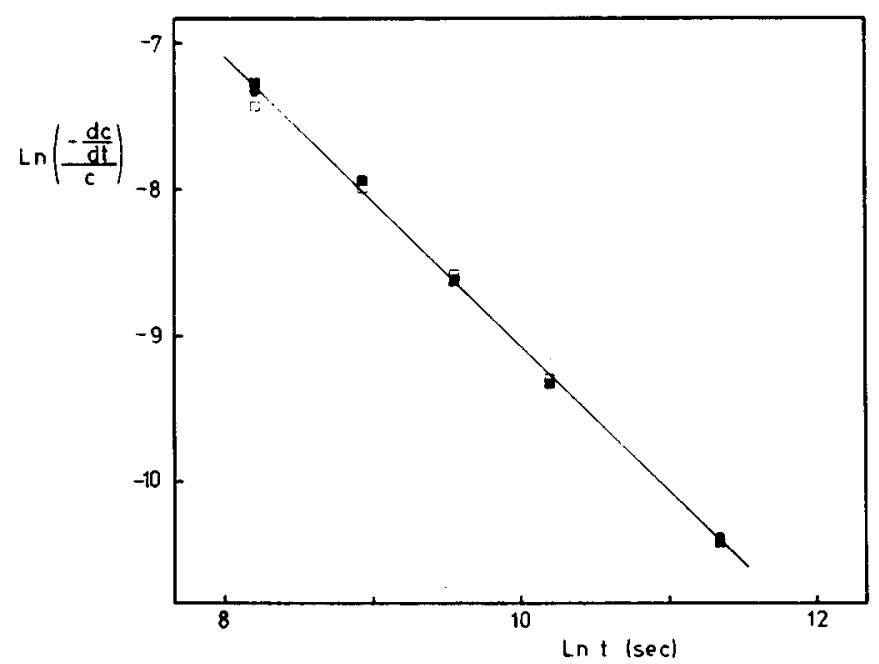

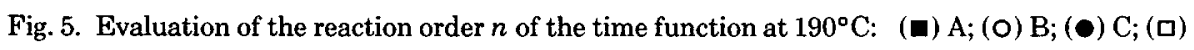
D. 
The SSP rate depends both on the concentration and the reciprocal reaction time. The intercept $\ln k$ is independent of $c_{0}$, and $k$ is a dimensionless number with a value of 0.28 . Equation (8) can also be written as

$$
-\frac{d c}{c}=k \frac{d t}{t}
$$

and its integrated form is

$$
-\ln \frac{c}{c_{0}}=k \ln \frac{t}{\tau}
$$

The logarithmic function in $(t / \tau)$ can only have a real value if $\tau>0$. This means that eqs. (8) and (10) only hold for a part of the reaction process, and it is important to know what the value of $\tau$ is and on what it depends. Therefore, the progress of the reaction was studied with different starting concentrations and at different temperatures.

\section{Starting Concentrations}

The SSP was studied on samples with widely different starting concentrations at $190^{\circ} \mathrm{C}$, and the results are given in Figure 6 . The reaction data fall predominantly on straight lines. The lines have all the same slope. The top line is of the sample with the lowest $c_{0}$ (the highest molecular weight), and the bottom curve is of the sample with the highest initial end-group concentration. The intercept with the zero conversion line is $\tau$, and the value of $\tau$ increases with decreasing $c_{0}$ (increasing molecular weight).

At the longer reaction times, the lines tend to curve; this may be due to a slight imbalance of the reactive groups at high conversion, or to degradation (decarboxylation). As all the lines have the same slope, it is possible to make a master curve with a wider span than each of the individual curves. To this end, the curves were shifted on the time axis, and the results are given in Figure 7. The slope of the linear part is again $k$, and at low conversions $(0-30 \%)$ the reaction data deviate from the linear function. So the relationships (8) and (10) hold only for conversions of over $30 \%$. The dependence of $\tau$ on $c_{0}$ may have the following form:

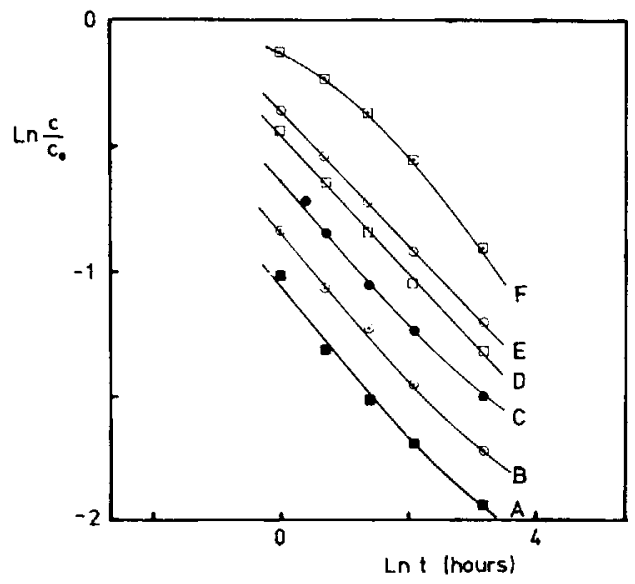

Fig. 6. Influence of starting concentration on progress of reaction at $190^{\circ} \mathrm{C}$. 


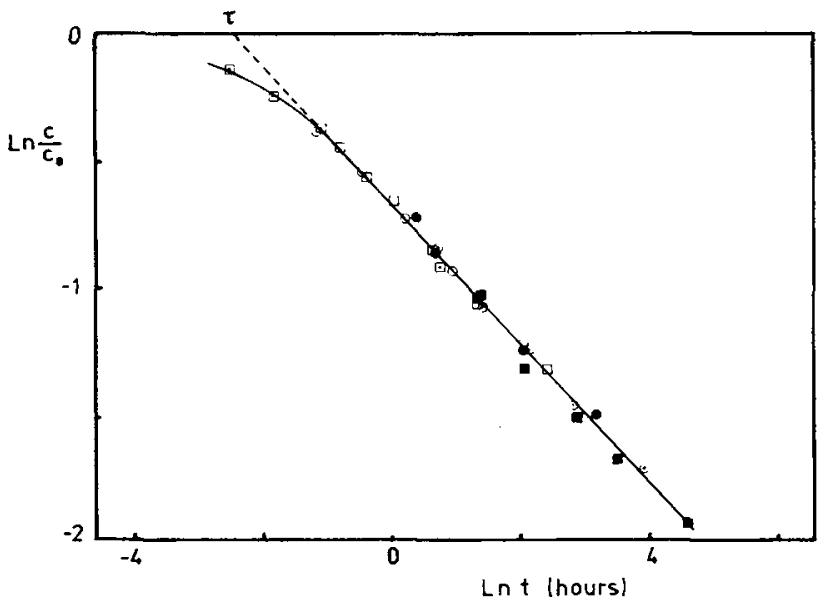

Fig. 7. Master curve influence of starting concentration on progress of reaction at $190^{\circ} \mathrm{C}$. Nor-

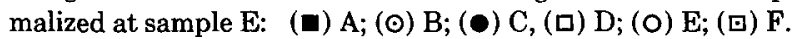

$$
\ln \tau=\ln \tau_{c=1}+m \ln c_{0}
$$

The $\tau_{c=1}$ is the $\tau$ at $1 \mathrm{meq} / \mathrm{g}$ and $190^{\circ} \mathrm{C}$. The results follow this relationship reasonably well (Fig. 8). For $m$, a value of -1.76 was obtained.

\section{Reaction Temperature}

The influence of temperature on the reaction rate function in a well-stirred system is on the reaction rate constant $k$. The effect of temperature on the SSP was studied on a sample with $c_{0}$ of $0.158 \mathrm{meq} / \mathrm{g}$ in the temperature range 115$205^{\circ} \mathrm{C}$, and the data are given in Figure 9. The lines are curved at low conversions, but at higher conversions they are linear and parallel. This suggests that in this parallel region, $k$ is independent of the reaction temperature but that the reaction temperature changes the $\tau$.

If a time shift is applied, again a mastercurve is obtained (Fig. 10). The linear

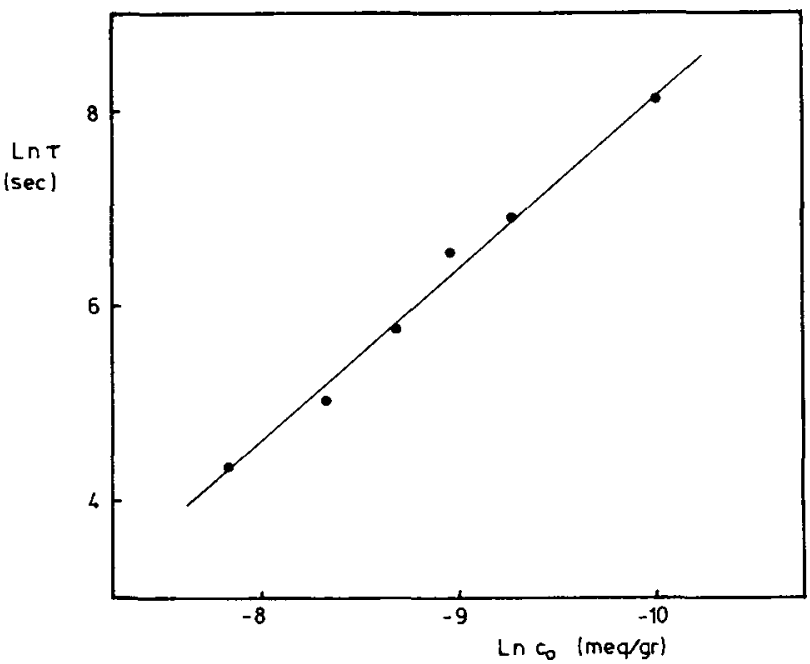

Fig. 8. Influence of starting concentration $\left(c_{0}\right)$ on $\ln \tau$ at $190^{\circ} \mathrm{C}$. 


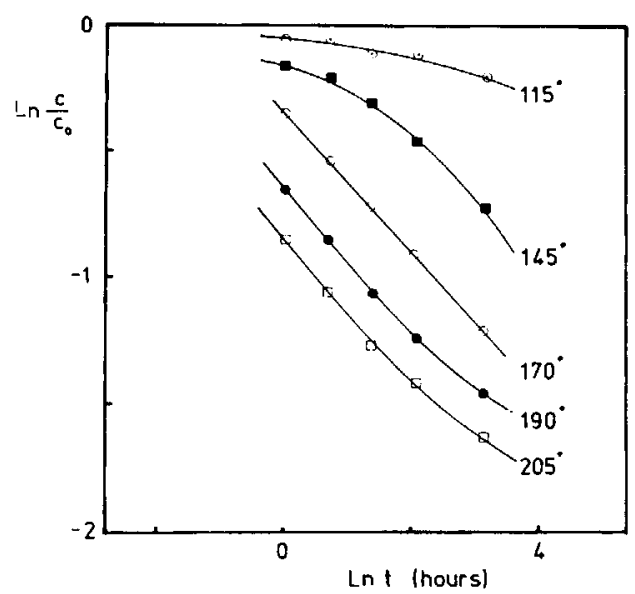

Fig. 9. Influence of reaction temperature on progress of reaction (sample $\mathrm{C}$, with $c_{0}=0.158$ $\mathrm{meq} / \mathrm{g})$.

relationship holds here too for conversions over $30 \%$, and the slope $k$ here was 0.27 , which is the same as observed earlier.

The influence of temperature on $\tau$ was evaluated with an Arrhenius-type relationship:

$$
\ln \tau=\ln \tau_{0}+\frac{E}{R T}
$$

Figure 11 shows that this relationship holds well. For sample $\mathrm{C}$ with $c_{0} 0.158$ $\mathrm{meq} / \mathrm{g}, \ln \tau_{0}$ was found to be $-21.3 \mathrm{~s}$, and $E$ was $105 \mathrm{~kJ} / \mathrm{mol}$.

\section{CONCLUSIONS}

The rate of polycondensation in the solid state does not follow the polyamidation kinetics of melt polymerization. We found the autocatalyzed SSP to be slowed down with reaction time, while the $\mathrm{H}_{3} \mathrm{PO}_{4}$-catalyzed reaction continued

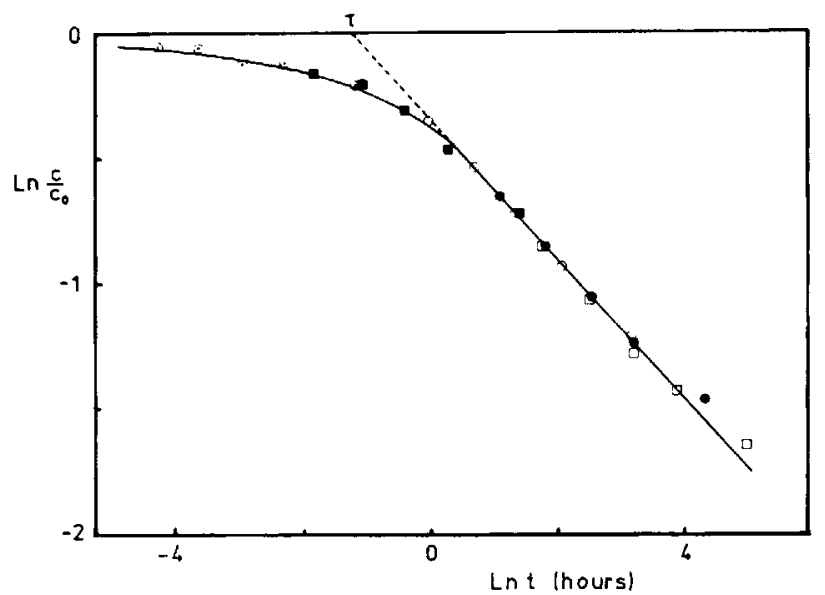

Fig. 10. Master curve influence of reaction temperature on progress of reaction (sample $\mathrm{C}$, with

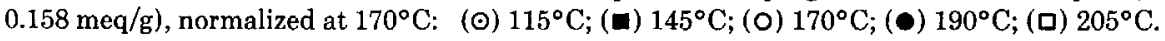




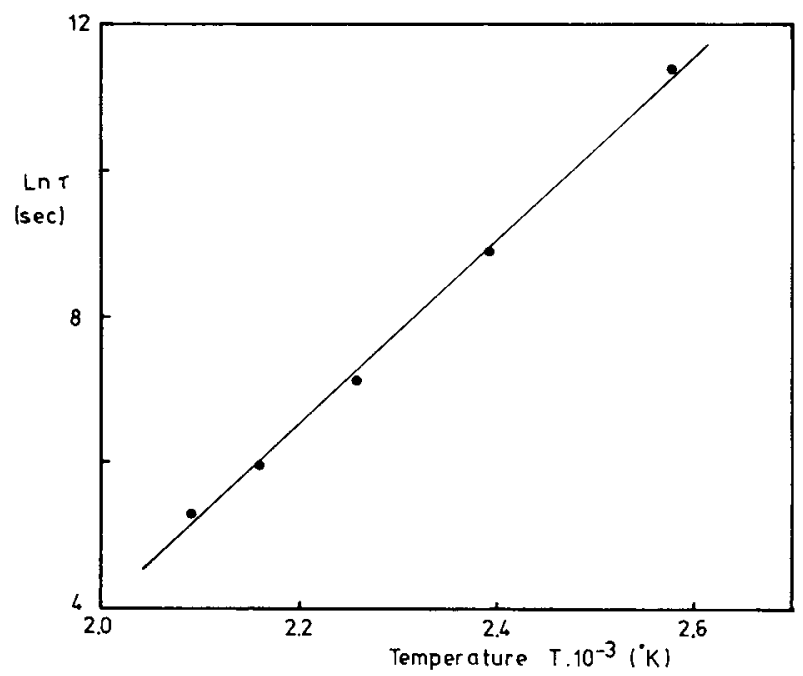

Fig. 11. Effect of temperature on $\ln \tau$ (sample C).

undisturbed. The catalyzing group has to diffuse, and the diffusion of the autocatalyzing chain end group is much lower than that of $\mathrm{H}_{3} \mathrm{PO}_{4}$; hence the diffusion if the autocatalyzing acid chain end group seems to be the reaction-limiting step.

Most intriguing was the influence of the starting molecular weight. We found, like others did before us, ${ }^{10}$ that the higher the starting molecular weight of the sample, the faster the rate of reaction in the solid state. This was found to be not an annealing effect of the crystalline structure or a molecular weight or concentration effect but an end group-to-end group distance distribution effect. As in the solid state the chains are frozen in, only the nearest groups will react easily, the distribution of the end group-to-end group distances will change and the diffusion distance will increase. (8)]:

The kinetics of the SSP reaction was found to have the following form [eq.

$$
-\frac{d c}{d t}=k \frac{c}{t}
$$

The reaction rate is first order in the concentration and reciprocal in the reaction time. This equation seems to combine the relationships observed by Griskey et al. ${ }^{3,4}$ and Oya et al. ${ }^{5}$

In SSP, there seems to be more than one region and the observed relationship holds only for conversions of over $30 \%$. Unusual too is that the rate constant $k$ is independent of temperature; it is a dimensionless number with a value of 0.28 . The time to reach $30 \%$ conversion however depends on both starting concentration and temperature.

For practical purposes, the integrated form, eq. (10), is more useful:

$$
-\ln \frac{c}{c_{0}}=k \ln \frac{t}{\tau}
$$

And $\tau$ is both dependent on $c_{0}$ and temperature, as given in eqs. (11) and (12) and combined as follows:

$$
\ln \tau=-24.6-1.76 \ln c_{0}+\frac{E}{R T}
$$


where the times $t$ and $\tau$ are in seconds, the concentration $c_{0}$ is in meq $/ \mathrm{g}$, and $E$ has a value of $105 \mathrm{~kJ} / \mathrm{mol}$.

From a study on the SSP of copolyamides, ${ }^{17}$ it was found that the temperature effect was not dependent on the degree of undercooling from the melt temperature. The often applied in-polymer diffusion WLF transformation, ${ }^{18}$ particular in the temperature region $T_{g}$ to $\left(T_{g}+100^{\circ}\right)$, did not give for our SSP a better correlation than the Arrhenius relationship in the region $115-205^{\circ} \mathrm{C}$.

The SSP rate at a particular temperature and concentration depends also on the starting concentration. This means that if one wants to synthesize material with SSP to a high or very high MW, the reaction time is strongly dependent on the starting concentration (MW). A lower starting concentration can be obtained by reacting longer in the melt or alternatively by introducing a remelting step in the SSP procedures.

The authors wish to thank Professors A. Bantjes and J. Schuijer for their stimulating discussions and are grateful to Ir. H. Jacobs and Mr. J. Fransen of the Central Laboratory DSM, in Geleen, for their active interest in the project.

\section{References}

1. P. J. Flory, U.S. Pat. 2,173,373 (1939).

2. L. B. Sokolov, Solid Phase Polymerization, Syntheses by Polycondensation, Publ. Israel Program for Scientific Translation, 1968, p. 73.

3. D. B. Jacobs and J. Zimmermann, Polymerization Processes, High Polymers Vol. XXIX, C. E. Schildknecht and I. Skeist, Eds., Wiley-Interscience, New York, 1977, p. 424.

4. R. G. Griskey and B. I. Lee, J. Appl. Polym. Sci., 10, 105 (1966).

5. F. C. Chen, R. G. Griskey, and G. H. Beyer, AIChEJ., 15, 680 (1969).

6. S. Oya, M. Tomioka, and T. Araki, Kubunshi Kagaka, 23, 254, 415 (1966).

7. A. Mattiussi and G. B. Gechele, Chem. Ind., 53, 662 (1971).

8. W. H. Bonner, U.S. Pat. 3,088,794 (1963).

9. R. Gabler and V. Tsender, Khim. Tekhnol. Polim., 1, 90 (1960).

10. G. C. Monroe, U.S. Pat. 3,031,433 (1962).

11. K. Wangermann and H. G. Zachmann, Prog. Colloid Polym. Sci., 57, 236 (1975).

12. D. M. W. van der Ham, Chem. Ind. (London), 730 (1972).

13. G. B. Taylor, J. Am. Chem. Soc., 69, 635 (1947).

14. J. E. Walz and G. B. Taylor, Anal. Chem., 19, 441 (1947).

15. J. Brandrup and E. H. Immergut, Eds., Polymer Handbook, 2nd ed. Wiley, New York, 1974, Chap. IV.

16. C. H. Bamford and C. F. H. Tipper, Chemical Kinetics, Vol. 2, Elsevier, Amsterdam, 1969, Chap. 5.

17. R. J. Gaymans, unpublished results.

18. J. N. Hay, in Flow Induced Crystallization in Polymer Systems, R. L. Millr, Ed. Gordon and Breach, New York, 1979, p. 69.

Received October 21, 1981

Accepted January 5, 1982 